Revista de la red interuniversitaria de estudios sobre las literaturas rioplatenses contemporáneas en Francia

$10 \mid 2014$

El XIX en el XX

\title{
“El hombre de los sesos", Microbios (2006)
}

\section{Diego Vecchio}

\section{OpenEdition}

\section{Journals}

Edición electrónica

URL: http://journals.openedition.org/lirico/1657

DOI: $10.4000 /$ lirico. 1657

ISSN: 2262-8339

Editor

Réseau interuniversitaire d'étude des littératures contemporaines du Río de la Plata

Referencia electrónica

Diego Vecchio, "EI hombre de los sesos", Microbios (2006)», Cuadernos LIRICO [En línea], 10 | 2014

Puesto en línea el 01 marzo 2014, consultado el 10 mayo 2019. URL : http://journals.openedition.org/ lirico/1657 ; DOI : 10.4000/lirico.1657

Este documento fue generado automáticamente el 10 mayo 2019

\section{(c) (i) (9)}

Cuadernos LIRICO está distribuido bajo una Licencia Creative Commons Atribución-NoComercialSinDerivar 4.0 Internacional. 


\title{
"El hombre de los sesos", Microbios (2006)
}

\author{
Diego Vecchio
}

1 El 13 de diciembre, las efemérides patagónicas celebran la Fiesta del Petróleo. Aquel día, como muchos recordarán, hace ya muchos años, un perro que erraba por las calles de Comodoro Rivadavia, al escarbar una fosa para enterrar un hueso, descubrió una baba negra y espesa que salía de las entrañas de la tierra, repugnantemente, a borbotones, que no era excremento de diablo, sino hidrocarburos parafínicos. Es de lamentar que muy pocos sepan que aquel mismo día, a unos pocos metros de este primer pozo petrolífero, también nació Evaristo Robustiniano Torres, el novelista más brillante del por aquel entonces territorio nacional. Si a Comodoro Rivadavia el petróleo le aportó riqueza material, las novelas de Evaristo Robustiniano Torres le dieron riqueza espiritual. Aún hoy, mientras los padres trabajan como ingeniero o secretaria bilingüe con experiencia en una destilería de petróleo, en las escuelas patagónicas los hijos aprenden las primeras letras con sus novelas.

2 Evaristo Robustiniano Torres tuvo la genialidad de inventar a Victricius que era al conde Drácula lo que el ñandú es al avestruz y lo que el puma es al tigre: una especie sudamericana más pequeña y menos agresiva de vampiro. Las novelas de Evaristo Robustiniano Torres contaban aventuras sanguíneas más que sangrientas en perfecta consonancia con los progresos de la hematología.

3 En 1628, William Harvey descubrió los movimientos del corazón y la circulación de la sangre en los animales. En 1882, Metchnikof comprendió la importancia del leucocito en la defensa del organismo. Con el nacimiento de Victricius, la ficción se adelantó a la ciencia. Evaristo Robustiano Torres inventó un vampiro cuyas papilas gustativas podían identificar, a partir de una gota extraída de la carótida de la víctima, la composición química de la sangre. En menos de un minuto, Victricius podía saber, con un margen mínimo de error, aquello que la ciencia todavía no era capaz de conocer : la cantidad de glóbulos rojos, blancos, plaquetas, urea, prótidos, glucosa, cloro, sodio, hierro, calcio, fósforo, fibrina y lípidos. Sobre todo lípidos. 
4 En aquella época, la Argentina era un país de vacas gordas, con hombres gordos y mujeres gordas, que bamboleaban sus carnes por los dos millones de metros cuadrados de superficie, ocupando aquellas soledades con su exceso de peso y volumen. Los argentinos comían un promedio diario de $1500 \mathrm{~g}$. de carne vacuna, acompañada por una escuálida ensalada. Las carnes rojas, ricas en proteínas, contienen sin embargo lípidos que se adhieren a las arterias, produciendo enfermedades coronarias y cerebrovasculares. No era de extrañar que la causa principal de mortalidad fueran los infartos y los derrames cerebrales, causados por esta dieta alta en grasas saturadas.

5 De este problema de salud pública, Evaristo supo hacer una fuente de inspiración. Victricius era un vampiro que solo le chupaba la sangre a individuos con problemas de sobrepeso. Si la tasa de colesterol presente en la sangre era inferior a los $2000 \mathrm{mg}$. por litro, Victricius abandonaba inmediatamente la presa. Si era superior, a la dentellada de inspección sucedía una dentellada de purificación, cuyo objetivo era no solo alimenticio sino también terapéutico.

6 La dentellada del vampiro clásico es indiferenciada, movida por el mal y solo busca vaciar a la víctima de sus fluidos vitales, a fin de transformarla en vampiro. La dentellada de Victricius era altamente selectiva, movida por el soberano bien de la salud y solo succionaba lípidos y nada más que lípidos. Al despertarse, la víctima se sentía ligera, como si en vez de haber comido 1,5 Kg. de asado con achuras, hubiera ingerido $250 \mathrm{gr}$. de arroz hervido.

7 Victricius era un vampiro del Nuevo Mundo, lleno de bondad y don de gentes. No como los vampiros del Viejo Continente, movidos por la destrucción. Muchas veces, al no encontrar más que víctimas subalimentadas, tuvo que conformarse con chuparle la sangre a alguna oveja. Prefería su propio desfallecimiento a provocar el desfallecimiento en el prójimo por absorción sanguínea. He aquí la revolución lanzada por Evaristo Robustiniano Torres : considerar a Victricius, no desde el punto de vista de las novelas de terror sino desde el punto de vista de la hematología. Los vampiros ya no eran los embajadores del mal, sino caballeros de la ciencia, al servicio del progreso.

Sus primeras historias fueron publicadas en una revista médica, a fin de introducir un poco de distracción entre los arduos artículos que hablaban de la genética de las moscas del vinagre o del descubrimiento de la luteína. Lo útil siempre ha de estar asociado a lo agradable, decían nuestros ancestros. La máxima no deja de tener actualidad. Las historias de Evaristo Robustiniano Torres fueron un verdadero éxito. Cuando quiso acordarse, los distintos episodios formaban una novela, que al ser publicada, se agotó rápidamente.

9 Este triunfo lo llevó a escribir una segunda y luego una tercera y una cuarta y una quinta novela por entregas. Los episodios brotaban de su pluma como el petróleo del suelo patagónico, dejando en los márgenes y sobre la mesa, manchas de tinta. Mientras la obra de Evaristo Robustiniano Torres crecía, también se extendían, al mismo ritmo, las destilerías de petróleo patagónico. Al poco tiempo, ya tenía una saga de cincuenta novelas, con los distintos momentos de la vida de Victricius, desde la primera infancia hasta su feliz vejez, rodeado por el afecto de sus hijos, nietos y bisnietos vampiros, domiciliado en las altas cumbres andinas.

Su fama trascendió las fronteras patagónicas. Evaristo Robustiniano Torres viajaba muy a menudo a la capital, para dar conferencias, asistir a cócteles, hablar por la radio. No podía caminar por las calles sin ser reconocido por algún lector, que le decía : “Apuesto a que en 
su próxima novela Victricius intentará hacerle bajar la tasa de colesterol a esa pobre mujer que pesa más de $120 \mathrm{Kg}$. y que no puede dejar de comer embutidos...". Evaristo Robustiniano Torres respondía : "Veremos, veremos".

11 Con todo el dinero que ganó, se construyó una casa de campo patagónica, al borde de un acantilado, con vista desde la ventana de su cuarto a una destilería de petróleo. Sus historias de vampiros se gestaban en las caminatas que daba por el borde de la playa, entre el mar y el desierto, mirando una de las chimeneas que dejaba escapar en la atmósfera gases tóxicos y llamas verdiazules.

12 Aquí comenzó a escribir los primeros episodios de su quincuagésima primera novela, su obra maestra sin ninguna duda, intitulada "El mal de Wöhler". A la edad de setenta y cinco años, por culpa de una degeneración del sistema nervioso que adviene con la vejez, descripta por primera vez por Friedrich Wöhler hacia la misma época, las papilas gustativas de Victricius pierden sensibilidad y nuestro amable vampiro comienza a cometer groseros errores de análisis. Victricius le absorbe los lípidos de manera indistinta a cuanto individuo se le pone al alcance del colmillo. En los individuos con una tasa de colesterol elevada, la dentellada no presenta ningún problema. En cambio, en los individuos con una tasa de colesterol normal o baja, el mordisco resulta fatal.

El colesterol es una sustancia indispensable para la vida. El organismo la utiliza para segregar bilis, hormonas y vitamina D. Y no solo esto. Este esterol, que se presenta bajo la forma de cristales blancos nacarados, es un componente esencial para las membranas celulares, sobre todo para las neuronas. En individuos endebles, la caída abrupta de la tasa de colesterol puede generar la muerte : una muerte hipolípida.

列 quererlo, Victricius se transforma en un asesino, con un haber de quince víctimas. La policía no sabe qué hacer. Nunca han tenido un caso parecido. Los cadáveres tienen una marca en el cuello. Pero los médicos forenses que realizan las autopsias no pueden dar con la causa del fallecimiento.

15 Y Victricius está a punto de hincarle el diente en el cuello a una bella muchacha subalimentada, con una tasa espeluznantemente baja de colesterol, sumida en un sueño profundo. Como es una noche de verano con luna llena, la muchacha ha dejado las ventanas de su cuarto abiertas de par en par. Inútil es decir que la absorción de los lípidos va a provocar una verdadera hecatombe hematológica. Y Victricius no lo sabe. Lo que plantea un espinoso problema: ¿se es culpable de una muerte que no se premeditó ? Los lectores estaban en vilo y seguían la publicación de cada episodio con los nervios de punta.

Fue entonces cuando ocurrió el accidente.

17 Evaristo Robustiniano Torres salía de un cóctel. Al cruzar un semáforo en amarillo, a toda velocidad, con su automóvil descapotable, hay que reconocerlo : con algunos miligramos de whisky en el torrente sanguíneo, otro automovilista que venía de una calle perpendicular, con un automóvil también descapotable, cruzó la misma avenida, también a toda velocidad, con el semáforo en rojo. El choque fue inevitable. El otro conductor murió en el acto. Evaristo Robustiniano Torres pasó a través del parabrisas y terminó despatarrado en el pavimento, con los brazos abiertos y una aureola de líquido encefálico alrededor del cráneo, hundido inquietantemente en la región occipital. Podría haber sido peor. Siempre puede ser peor. Por suerte, la ambulancia llegó a tiempo. Los enfermeros recogieron los restos de materia gris y blanca que encontraron en la calle, guardándola en 
una probeta esterilizada y lo llevaron al hospital más cercano. Gracias a estos primeros auxilios, Evaristo Robustiniano Torres no murió. Pero quedó en coma. La noticia conmovió a la opinión pública. Sus lectores no dejaron de enviarle flores y cartas que Evaristo Robustiniano Torres no podía ni oler ni leer. 